\title{
Perancangan Instalasi Pengolahan Air Limbah (IPAL) Industri Kertas Halus
}

\author{
Mohammad Rosidi dan Mohammad Razif \\ Jurusan Teknik Lingkungan, Fakultas Teknik Sipil dan Perencanaan, Institut Teknologi Sepuluh Nopember (ITS) \\ Jl. Arief Rahman Hakim, Surabaya 60111 Indonesia \\ e-mail: razif@its.ac.id
}

\begin{abstract}
Abstrak-Industri kertas merupakan industri yang menghasilkan limbah cair dalam jumlah besar. Selain itu kandungan parameter pencemar dalam proses pewarnaan kertas sangat tinggi. Berdasarkan PerGub Jatim no. 72 tahun 2013 terdapat 5 parameter baku mutu air limbah yang harus dipenuhi sebelum dibuang ke badan air. Adapun parameter yang perlu diolah adalah pH, COD, BOD, TSS,dan Pb. Pada perancangan digunakan data primer berupa data debit dan karakteristik limbah yang diambil dari industri kertas halus PT.X Sidoarjo. Limbah yang diolah berasal dari proses pewarnaan kertas. Karakteristik limbah yang diolah memiliki nilai TSS41000 mg/l, COD $45384 \mathrm{mg} / \mathrm{l}$, BOD $8300 \mathrm{mg} / \mathrm{l}, \mathrm{Pb} 0,56 \mathrm{mg} / \mathrm{l}$ dan pH 7,7.Unit IPAL yang direncanakan terdiri atas prasedimentasi, bak ekualisasi, bak pengaduk cepat, bak pengaduk lambat, sedimentasi 2, dan ABR-ABF. Perhitungan BOQ dan RAB menggunakan HSPK Kota Surabaya 2015 dan didapat angka sebesar Rp217.650.760 untuk pembangunan seluruh unit IPAL.
\end{abstract}

Kata Kunci-ABR, ABF ,desain IPAL, industri kertas, limbah cair

\section{PENDAHULUAN}

$\mathrm{I}^{\mathrm{I}}$ INDUSTRI kertas merupakan kegiatan yang dapat menimbulkan dampak besar terhadap kualitas sumber daya alam. Dalam proses produksinya air merupakan komponen yang memegang peranan penting karena setiap tahapan serta proses dalam produksi kertas menggunakan air[1]. Banyaknya jumlah air yang digunakan juga berdampak pada produksi limbah cair yang dihasilkan. Limbah cair yang tidak terolah dapat menyebakan pencemaran baik pada badan air maupun tanah sehingga diperlukan proses pengolahan pada limbah tersebut.

Pengolahan limbah cair dapat dilakukan secara fisik-kimia maupun secara biologis. Secara fisik-kimia teknologi atau alternatif pengolahan yang digunakan diantaranya adalah proses sedimentasi, koagulasi-flokulasi, oksidasi kimia dll[2]. Secara proses biologi adapun alternatif yang dapat digunakan dapat berupa degradasi menggunakan bakteri dengan proses aerob maupun anaerobik. Pemilihan unit pengolahan tersebut perlu menyesuaikan karakteristik limbah yang dihasilkan.

\section{METODE PERENCANAAN}

\section{A. Pengumpulan Data}

Pengumpulan data dilakukan untuk mengumpulkan data yang diperlukan dalam perencaaan IPAL. Data yang dikumpulkan terdiri atas data primer dan data sekunder. Datadata yang diperlukan meliputi:

1) Data Primer

- Karakteristik air limbah

- Debit air limbah per hari

2) Data Sekunder

- Gambaran umum perusahaan yang didapat dari profil perusahaan

- Baku mutu pengolahan aor limbah untuk kegiata/usaha industri kertasyang diperoleh dari PerGub Jatim no. 72 Tahun 2013 ${ }^{[3]}$

- Harga Satuan Pokok Kerja (HSPK) Kota Surabaya tahun $2015^{[4]}$

\section{B. Pengolahan dan Analisis Data}

Pengolahan data meliputi perhitungan debit, penetapan baku mutu effluent air limbah sesuai PerGub Jatim No. 72 tahun 2013[3], penentuan unit pengolahan, perhitungan unit IPAL, penggambaran DED (Detail Engineering Design), perhitungan BOQ (Bill of Quantity) dan RAB (Rencana Anggaran Biaya) [4].

\section{Hasil dan Pembahasan}

Data yang telah dianalisis selanjutnya diolah dilakukan pembahasan terhadap hasil dari perhitungan unit bangunan yang didesain. Selain itu dilakukan pembahasan terhadap nilai BOQ dan RAB yang telah diperoleh.

\section{HASIL DAN PEMBAHASAN}

\section{A. Debit Limbah Industri Kertas Halus PT.X}

Debit pengolahan yang digunakan dalam desain adalah 10 $\mathrm{m}^{3} /$ hari. Adapun debit peak yang digunakan adalah 0,24 1/detik. Debit limbah cair yang diolah berasal dari kegiatan pewarnaan kertas.

\section{B. Karakteristik Limbah Cair Industri Kertas Halus}

Limbah yang disampling berasal dari kegiatan pewarnaan kertas. Limbah tersebut meiliki karakteristik kandungan padatan yang tinggi serta warna yang pekat. Karakteristik limbah disajikan pada Tabel 1. 
Tabel 1.

Karakteristik Limbah Cair Industri Kertas Halus

\begin{tabular}{ccccc}
\hline \hline No. & Parameter & Satuan & $\begin{array}{c}\text { Baku } \\
\text { Mutu Air } \\
\text { Limbah* }\end{array}$ & $\begin{array}{c}\text { Hasil } \\
\text { Analisa }\end{array}$ \\
\hline 1 & $\mathrm{pH}$ & - & $6-9$ & 7,7 \\
2 & $\mathrm{TSS}$ & $\mathrm{mg} / \mathrm{L}$ & 70 & 41000 \\
3 & $\mathrm{COD}$ & $\mathrm{mg} / \mathrm{L} \mathrm{O}_{2}$ & 150 & 45384 \\
4 & $\mathrm{BOD}$ & $\mathrm{mg} / \mathrm{L} \mathrm{O}_{2}$ & 70 & 8300 \\
5 & Timbal & $\mathrm{mg} / \mathrm{L} \mathrm{Pb}$ & 0,1 & 0,56 \\
\hline \hline
\end{tabular}

*Sumber: PerGub Jatim No. 72 Tahun 2013.

Berdasarkan hasil analisa laboratorium, parameter yang masih belum memenuhi baku mutu adalah TSS, BOD, COD, dan Timbal. Sehingga IPAL didesain untuk menurunkan parameter yang tidak memenuhi baku mutu tersebut.

Nilai rasio BOD/COD dari karakteristik air limbah menunjukkan nilai $<0,3$ sehingga perlu pengolahan secara fisik-kimia. Pengolahan biologis dapat dilakukan setelah nilai $\mathrm{BOD} / \mathrm{COD}$ dari air limbah $>0,3$ atau tidak toksik bagi mikroorganisme.

\section{Perhitungan Detail Unit IPAL}

Unit IPAL yang didesain meliputi pengolahan secara fisikkimia serta proses biologis. Perhitungan tiap unit pengolahan mengacu pada kriteria desain yang diambil dari literatur[5]. Layout IPAL yang didesain disajikan pada Gambar 1.

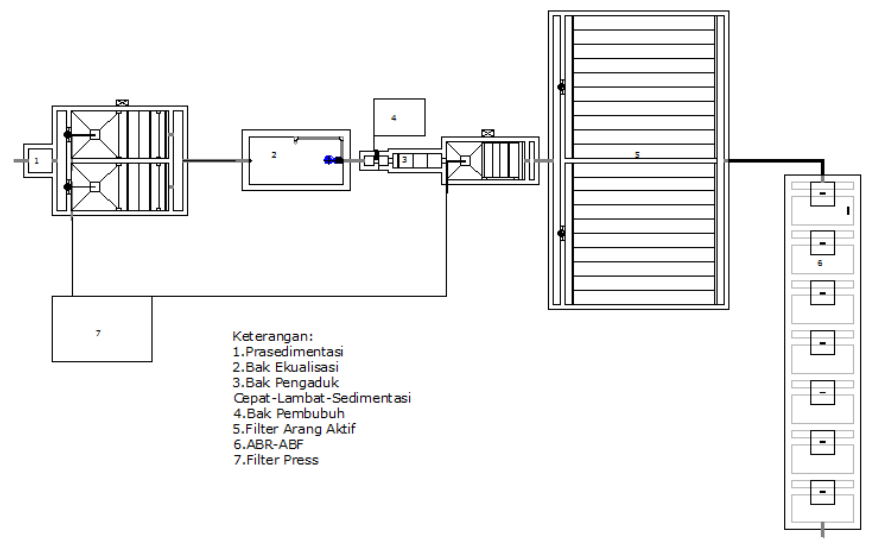

Gambar. 1. Layout IPAL rencana tanpa skala

\section{1) Prasedimentasi}

Prasedimentasi berfungsi untuk menurunkan padatan tersuspensi yang terdapat pada air limbah sebelum masuk ke bak ekualisasi. Bangunan prasedimentasi direncanakan berbentuk rectangular.

Pada desain bak prasedimentasi perlu didesain 4 zona secara terpisah. Potongan prasedimentasi disajikan pada Gambar 2.

- Dimensi Zona Pengendapan

$$
\begin{array}{ll}
\text { Panjang } & =2 \mathrm{~m} \\
\text { Lebar } & =1 \mathrm{~m} \\
\text { Kedalaman } & =1 \mathrm{~m}
\end{array}
$$

- Dimensi Zona Inlet

Pada zona inlet didesain pintu air dengan dimensi sebagai berikut:
Lebar $\quad=0,3 \mathrm{~m}$

Tinggi $=0,4 \mathrm{~m}$

- Dimensi Zona Lumpur

Jumlah Kompartemen $=2$ buah

Luas permukaan $\quad=1 \mathrm{~m}^{2}$

Luas dasar $\quad=0,01 \mathrm{~m}^{2}$

Kedalaman $\quad=0,3 \mathrm{~m}$

- Dimensi Zona Outlet

Jumlah gutter = 1 buah

Panjang gutter $\quad=1 \mathrm{~m}$

Lebar gutter $\quad=0,05 \mathrm{~m}$

Kedalaman $\quad=0,15 \mathrm{~m}$

2) Bak Ekualisasi

Bak ekualisasi berfungsi untuk meratakan aliran dan beban

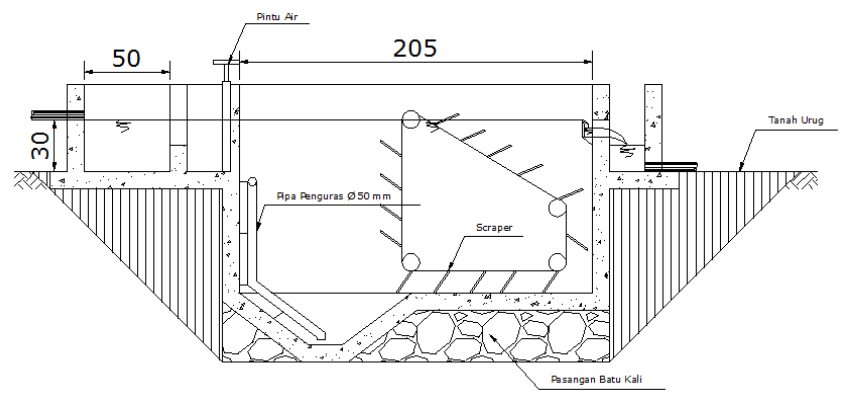

Gambar. 2. Potongan memanjang prasedimentasi tanpa skala

air limbah sebelum masuk ke pengolahan fisik-kimia dan biologis. Bak ekualisasi juga berfungsi sebagai bak penampung agar aliran air limbah pada unit selanjutnya dapat berlangsung secara kontinyu.

Dimensi Bak Ekualiasi

Panjang $=2 \mathrm{~m}$

Lebar $\quad=1 \mathrm{~m}$

Kedalaman $=1 \mathrm{~m}$

Pompa yang digunakan untuk mengalirkan air limbah dari bak ekualisasi ke unit selanjutnya adalah pompa submersible non clogging. Potongan memanjang bak ekualisasi disajikan

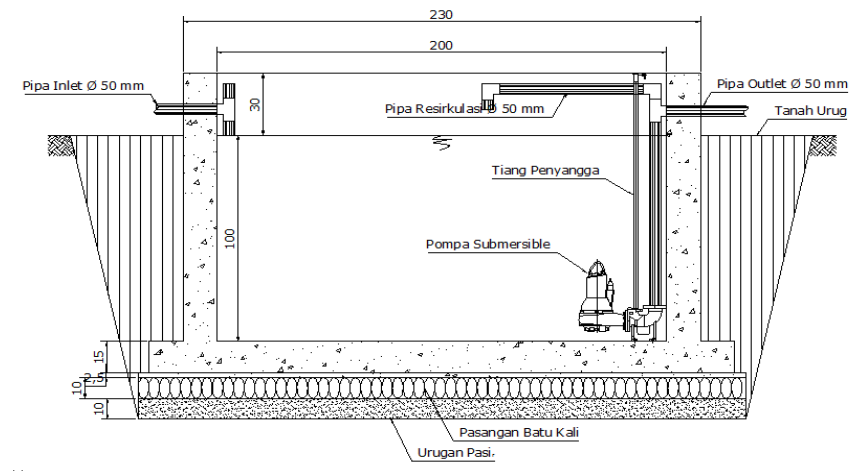

Gambar. 3. Potongan memanjang bak ekualisasi tanpa skala

pada Gambar 3.

\section{3) Bak Pengaduk Cepat-Pengaduk Lambat-Sedimentasi}

Bangunan pengadukan cepat-pengadukan lambat dan sedimentasi didesain menjadi satu kesatuan untuk mempermudah perawatan. Bangunan pengadukan cepatpengadukan lambat berfungsi untuk mendispersikan koagulan 
(koagulasi) dan membentuk flok (flokulasi) agar dapat diendapkan di bak sedimentasi.

Pada proses koagulasi-flokulasi digunakan 2 jenis koagulan yaitu PAC (Poly Aluminium Chloride) dan $\mathrm{MgO}$ (Magnesium Oksida). PAC dipilih karena dapat bekerja pada $\mathrm{pH}$ yang tinggi dan harga relatif murah. $\mathrm{MgO}$ selain berfungsi sebagai koagulan juga berfungsi menaikkan $\mathrm{pH}$ larutan sehingga memungkinkan terjadinya presipitasi logam timbal dalam air limbah. Dosis koagulan yang digunakan untuk PAC dan $\mathrm{MgO}$ secara berturut-turut adalah $250 \mathrm{mg} / \mathrm{l}$ dan $35 \mathrm{mg} / \mathrm{l}$.

Proses koagulasi didesain menggunakan terjunan. Terjunan dalam proses koagulasi digunakan karena mudah dalam perawatan.

- Dimensi Pengaduk Cepat

$\begin{array}{ll}\text { Gradien kecepatan } & =600 / \text { detik } \\ \text { Waktu detensi } & =30 \text { detik } \\ \text { Tinggi terjunan } & =1 \mathrm{~m} \\ \text { Panjang bak pengaduk cepat } & =0,2 \mathrm{~m} \\ \text { Lebar bak pengaduk cepat } & =0,2 \mathrm{~m} \\ \text { Kedalaman bak pengaduk cepat } & =0,1 \mathrm{~m}\end{array}$

Proses flokulasi menggunakan sistem pengadukan dalam sekat berlubang. Bak pengadukan lambat didesain dengan gradien kecepatan menurun dengan tujuan agar flok yang terbentuk tidak mudah pecah dan dapat diendapkan dengan baik dalam bak pengendap.

- Dimensi Pengaduk Cepat

Gradien kecepatan kompartemen $1=50 /$ detik

Gradien kecepatan kompartemen $2=40 /$ detik

Gradien kecepatan kompartemen $3=25 /$ detik

Waktu detensi kompartemen $1=5$ menit

Waktu detensi kompartemen $2=5$ menit

Waktu detensi kompartemen $3=5$ menit

Jumlah lubang kompartemen $1=4$ buah

Jumlah lubang kompartemen $1=6$ buah

Jumlah lubang kompartemen $1=9$ buah

Panjang bak pengaduk cepat $\quad=0,9 \mathrm{~m}$

Lebar bak pengaduk cepat $\quad=0,3 \mathrm{~m}$

Kedalaman bak pengaduk cepat $\quad=0,5 \mathrm{~m}$

Bak sedimentasi berfungsi mengendapkan flok dari proses koagulasi-flokulasi. Bak sedimentasi didesain berbentuk rectangular. Dalam desain bak sedimentasi juga perlu mempertimbangkan 4 zona seperti pada bak prasedimentasi.

- Dimensi Zona Pengendapan

$$
\begin{array}{ll}
\text { Panjang } & =1,6 \mathrm{~m} \\
\text { Lebar } & =0,8 \mathrm{~m} \\
\text { Kedalaman } & =0,7 \mathrm{~m}
\end{array}
$$

- Dimensi Zona Inlet

Zona inlet menggunakan outlet dari bak pengaduk lambat dengan dimensi:

Lebar $\quad=0,15 \mathrm{~m}$

Kedalaman $=0,15 \mathrm{~m}$

- Dimensi Zona Lumpur

Jumlah Kompartemen $=2$ buah

Luas permukaan $\quad=0,8 \mathrm{~m}^{2}$

Luas dasar $\quad=0,04 \mathrm{~m}^{2}$

Kedalaman $\quad=0,4 \mathrm{~m}$
- Dimensi Zona Outlet

$$
\begin{array}{ll}
\text { Jumlah gutter } & =1 \mathrm{buah} \\
\text { Panjang gutter } & =1 \mathrm{~m} \\
\text { Lebar gutter } & =0,05 \mathrm{~m} \\
\text { Kedalaman } & =0,15 \mathrm{~m}
\end{array}
$$

\section{4) Filter Karbon Aktif}

Filter karbon aktif berfungsi menyisihkan warna pada air limbah yang belum bisa disisihkan melalui proses koagulasiflokulasi. Selain itu filter karbon aktif juga berfungsi menyisishkan zat organik dalam air limbah. Hal ini disebabkan karena dalam filter karbon aktif terjadi proses adsorbsi sehingga padatan dalam air limbah dapat terserap ke dalam pori karbon.

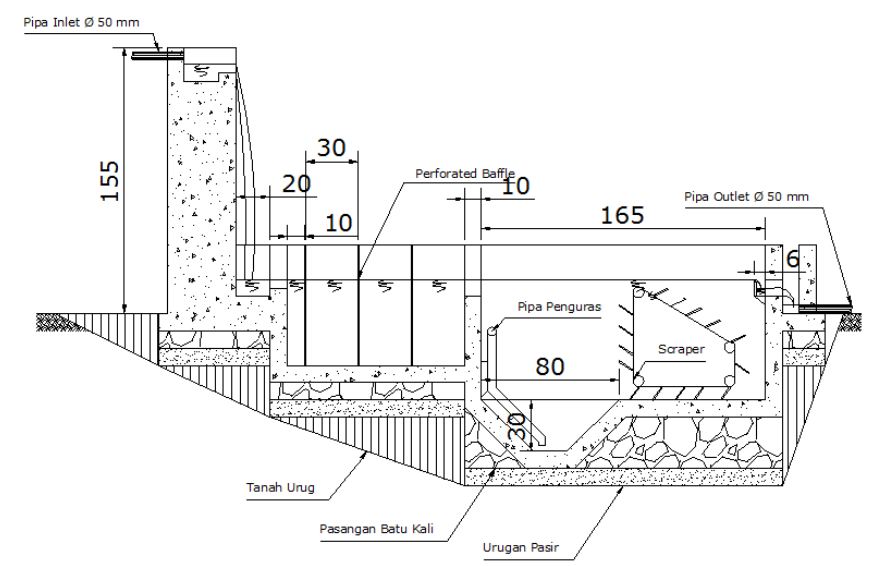

Gambar. 4. Potongan memanjang bak pengaduk cepat-pengaduk lambatsedimentasi tanpa skala

Desain filter karbon berbentuk kolom adsorbsi. Dimana desain dilakukan melalui proses scale up dari hasil percobaan laboratorium. Potongan filter karbon aktif disajikan pada Gambar 5.

- Dimensi Zona Outlet

Diameter kolom =0,3 buah

Panjang kolom $\quad=3 \mathrm{~m}$

Jumlah bak $\quad=2$ buah

Jumlah kolom per bak $=20$ buah

Konfigurasi kolom dalam bak:

Jumlah vertikal $\quad=10$ buah

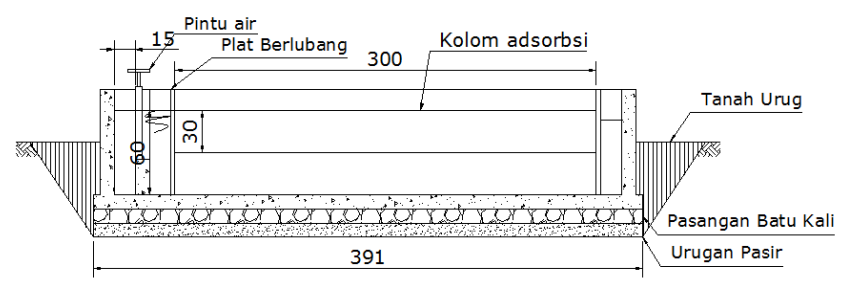

Gambar. 5. Potongan memanjang filter karbon aktif tanpa skala

Jumlah horizontal $=2$ buah

5) Anaerobic Baffled Reactor-Anaerobic Biofilm Reactor

Anaerobic Baffled Reactor (ABR) dan Anaerobic Biofilm

Reactor $(A B F)$ berfungsi menyisihkan zat organik dari air limbah. Pengolahan menggunakan ABR-ABF dilakukan setelah diperoleh nilai $\mathrm{BOD} / \mathrm{COD}>0,3$ yang diperoleh dari percobaan laboratorium.

ABR merupakan pengolahan biologis dengan sistem 
pertumbuhan tersuspensi. Sedangkan $\mathrm{ABF}$ merupakan pengolahan biologis dengan sistem terlekat. Kedua sistem tersebut memiliki kelebihan dalam menyisishkan zat organik dengan efisiensi yang tinggi, tahan terhadap, serta produksi lumpur yang kecil. Selain itu sistem pengolahan menggunakan ABR-ABF memungkinkan konstruksi reaktor yang tidak terlalu dalam. Potongan melintang ABR-ABF disajikan pada Gambar 6.

- Dimensi ABR

Panjang kompartemen $\quad=1,3 \mathrm{~m}$

Lebar kompartemen $\quad=0,6 \mathrm{~m}$

Kedalaman kompartemen $=1,5 \mathrm{~m}$

Jumlah Kompartemen $=5$ buah

- Dimensi ABF

Panjang kompartemen $\quad=1,3 \mathrm{~m}$

Lebar kompartemen $\quad=0,6 \mathrm{~m}$

Kedalaman kompartemen $=1,5 \mathrm{~m}$

Jumlah Kompartemen $=2$ buah

Jenis media yang digunakan adalah sarang tawon.

\section{Rencana Anggaran Biaya}

Perhitungan Rencana Anggaran Biaya (RAB) didasarkan pada HSPK Kota Surabaya Tahun $2015^{[3]}$. Berdasarkan hasil perhitungan diperoleh nilai RAB untuk kegiatan konstruksi IPAL sebesar Rp217.650.760.

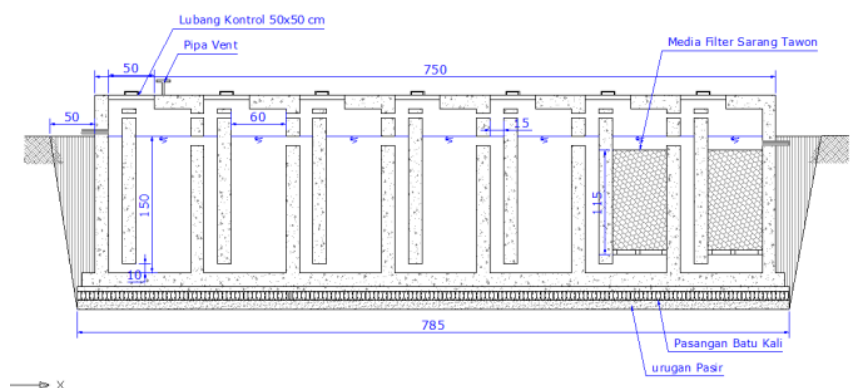

Gambar. 6. Potongan memanjang ABR-ABF tanpa skala

\section{KESIMPULAN}

Berdasarkan hasil perencanaan instalasi pengolahan air limbah (IPAL) diperoleh beberapa kesimpulan sebagai berikut:

1. Pengolahan yang dipilih unruk mengolah limbah pewarna industri kertas terdiri dari proses fisik-kimia dan proses bilogis.

2. Nilai Rencana Anggaran Biaya (RAB) konstruksi IPAL sebesar Rp217.650.760.

\section{DAFTAR PUSTAKA}

[1] Welasih, T, Penururnan BOD dan COD Limbah Industri Kertas dengan Air Laut Sebagai Koagulan. Jurnal rekayasa Perancangan vol 4 (2008).

[2] Pokhrel,D \& Viraraghavan,T. Treatment of Pulp and Paper Mill Wastewater-A Review. Sci.Tot.Env. Vol. 333 (2004) 37-58.

[3] Pemerintah Provinsi Jawa Timur. Peraturan gubernur Jawa Timur No. 72 Tahun 2013.

[4] Pemerintah Kota Surabaya. Harga Satuan Pokok Kerja Tahun 2015.
[5] Metcalf\&Eddy.Wastewater Engineering Treatment and Reuse $4^{\text {th }}$ Edition..Singapore: Mc. Graw Hill (2004). 